\title{
Pengendalian Heat Stress Pada Tenaga Kerja di Bagian Furnace PT. X Pangkalpinang Bangka Belitung
}

\author{
Gita Fajrianti.*), Zahroh Shaluhiyah**), Daru Lestantyo***) \\ *) Stikes Abdi Nusa Pangkalpinang \\ Korespondensi : gitafajrianti@ymail.com \\ **) Magister Promosi Kesehatan Universitas Diponegoro Semarang \\ ***) Bagian Kesehatan dan Keselamatan Kerja, FKM Universitas Diponegoro Semarang
}

\begin{abstract}
ABSTRAK
Tempat kerja yang nyaman merupakan salah satu faktor penunjang gairah kerja. Lingkungan kerja yang panas dan lembab akan menurunkan produktivitas kerja, juga akan membawa dampak negatif terhadap kesehatan dan keselamatan kerja. Suhu panas terutama berakibat menurunkan prestasi kerja berfikir. Penurunan kemampuan berfikir terjadi sesudah suhu udara melampaui suhu $32^{\circ} \mathrm{C}$. Suhu dilingkungan area furnace sebesar $34,9^{\circ} \mathrm{C}$, melebihi $N A B$ yang distandarkan sebesar $30,5^{\circ} \mathrm{C}$. Tujuan dari penelitiaan ini adalah untuk menganalisis pengendalian heat stress pada tenaga kerja dibagian furnace PT.X Pangkalpinang Kepulauan Bangka Belitung. Penelitian ini menggunakan pendekatan kualitatif dengan wawancara mendalam pada 8 informan utama, 5 orang tenaga kerja dibagian produksi dan 3 orang dari manajemen. Analisa data menggunakan metode content analysis. Hasil penelitian menunjukkan bahwa semua informan mengungkapkan suhu dilingkungan kerja area tanur panas sesuai dengan hasil pengukuran suhu dilapangan sebesar $34,9^{\circ} \mathrm{C}$ melebihi ambang batas yang distandarkan, pengendalian heat stress dengan training (pendidikan atau latihan tentang pengendalian heat stress dan mengendalikan resiko tekanan panas) belum rutin dilaksanakan, pengendalian dengan penggantian cairan sudah disediakan oleh perusahaan tetapi aturan dan pola konsumsi belum dilaksanakan, pengendalian dengan aklimatisasi belum dilaksanakan diperusahaan.
\end{abstract}

Kata Kunci: heat stress, pengendalian, pekerja

\begin{abstract}
Comfortable workplace is one of the factors supporting morale. The work environment is hot and humid will reduce labor productivity, it will also have negative impacts on health and safety. Warmer temperatures result in lower performance primarily thinking. Decreased ability to think happened after the temperature has exceeded $32^{\circ} \mathrm{C}$. The temperature within the furnace area of $34.9^{\circ} \mathrm{C}$, which exceeds the standardized NAV of $30.5^{\circ} \mathrm{C}$. The purpose of this is to research analyze control of heat stress on the workforce section furnace PT.X Pangkalpinang Bangka Belitung. This study used a qualitative approach with in-depth interviews on 8 key informants, 5 labor section of the production and management 3. Analysis of the data using content analysis. The results showed that all informants reveal the temperature within the furnace hot work area in accordance with the results of temperature measurements in the field at $34.9^{\circ} \mathrm{C}$ exceeds the threshold standardized, control heat stress with training (education or training on heat stress control and controlling the risk of heat stress) is not routinely executed, control with fluid replacement has been provided by the company but the rules and patterns of consumption
\end{abstract}


have not been implemented, control with acclimatization yet implemented in the company. Keywords: heat stress, control, worker

\section{PENDAHULUAN}

Iklim (cuaca) kerja adalah kombinasi dari suhu udara (suhu basah dan suhu kering), kelembaban udara, kecepatan gerakan udara, dan panas radiasi. Kombinasi keempat faktor tersebut yang dipadankan dengan produksi panas oleh tubuh sendiri disebut tekanan panas (heat stress). Iklim (cuaca) kerja mempengaruhi daya kerja. Produktivitas, efisiensi dan efektivitas kerja sangat dipengaruhi oleh kondisi iklim (cuaca) kerja (Suma'mur, 2009).

Menurut Manuaba, lingkungan kerja yang nyaman sangat dibutuhkan oleh pekerja untuk dapat bekerja secara optimal dan produktif. Oleh karena itu lingkungan kerja harus ditangani atau didesain sedemikian rupa sehingga menjadi kondusif terhadap pekerja untuk melaksanakan kegiatan dalam suasana yang aman dan nyaman.

Tempat kerja yang nyaman merupakan salah satu faktor penunjang gairah kerja. Lingkungan kerja yang panas dan lembab akan menurunkan produktivitas kerja, juga akan membawa dampak negatif terhadap kesehatan dan keselamatan kerja. Suhu panas terutama berakibat menurunkan prestasi kerja berfikir. Penurunan kemampuan berfikir demikian sangat luar biasa terjadi sesudah suhu udara melampaui suhu $32^{\circ} \mathrm{C}$. Suhu panas mengurangi kelincahan, memperpanjang waktu reaksi dan waktu pengambilan keputusan, menganggu kecermatan otak, mengganggu koordinasi saraf perasa dan saraf motoris. Kondisi panas yang berlebih - lebihan mengakibatkan rasa letih, kantuk, mengurangi kestabilan dan meningkatkan angka kesalahan kerja (Suma'mur, 1996).

Pengendalian terhadap heat stress dan heat strain dilaksanakan dalam rangka perlindungan keselamatan dan kesehatan tenaga kerja melalui upaya pencegahan. Apabila heat stress tidak dilakukan upaya pengendaliannya dapat mengakibatkan kedaruratan heat stress yaitu: heat rash, heat cramps, exhaustion dan heat stroke (Suma'mur, 2009).

PT.X merupakan perusahaan peleburan biji timah, dimana suhu peleburannya sebesar $1300^{\circ} \mathrm{C}$ dengan suhu ISBB dibagian furnace $34,9^{\circ} \mathrm{C}$ dan dibagian tapping $34,6^{\circ} \mathrm{C}$. Suhu ini melebihi nilai ambang batas (NAB) yang diperkenankan 
berdasarkan peraturan Menaker No pihak manajemen, setiap tenaga kerja yang Per.13/Men/X/2011 dengan waktu kerja baru langsung berada dilingkungan panas. yang sesuai yaitu $0 \%-25 \%$ dengan beban kerja berat ISBB adalah sebesar $30,5^{\circ} \mathrm{C}$. Dari 5 pekerja yang dilakukan survey pendahuluan mengeluh panas, banyak mengeluarkan keringat, haus, lelah dan mengantuk. Dari keringat yang keluar berlebihan, maka akan terjadi volume plasma berkurang sehingga volume darah juga berkurang, akibatnya tekanan darah turun dan pasokan $\mathrm{O}_{2}$ (oksigen) ke otak akan berkurang, dengan demikian orang akan kehilangan kesadarannya. Kejadian ini merupakan pengaruh panas (respons) terhadap tubuh tenaga kerja yang jika dibiarkan terus menerus akan mengakibatkan pengaruh negatif berupa gangguan pekerjaan dan kesehatan.

Hasil studi pendahuluan melalui wawancara dan observasi bahwa pengendalian heat stress di perusahaan belum berjalan secara optimal. Pengendalian dengan training (pendidikan/latihan) baru sebatas induksi untuk karyawan baru dan penyuluhan atau pembinaan K3 yang belum rutin. Pengendalian dengan penggantian cairan, dari pihak manajemen menyediakan air minum yang cukup ditempat istirahat, tapi belum ada himbauan atau saran sebaiknya untuk penggantian cairan. Pengendalian dengan aklimatisasi tidak dilakukan oleh

\section{METODE PENELITIAN}

Jenis penelitian ini adalah penelitian kualitatif. Penelitian kualitatif adalah sejenis penelitian yang secara khusus menggunakan teknik untuk memperoleh jawaban atau informasi mendalam tentang pendapat, persepsi, dan perasaan seseorang. Disajikan secara deskriptif eksploratif dengan melalui observasi dan wawancara mendalam (indepth interview). Wawancara mendalam merupakan salah satu teknik pengumpulan data kualitatif, yang dilakukan antara informan atau responden dengan pewawancara yang terampil, yang ditandai dengan penggalian mendalam tentang segala sesuatu tentang masalah penelitian dengan menggunakan pertanyaan terbuka (Lapau, 2012)

Jenis penelitian yang dilakukan ini adalah penelitian kualitatif bersifat deskriptif eksploratif untuk menjelaskan sistem metode pengendalian heat stress pada tenaga kerja dibagian furnace. Subyek penelitian dalam penelitian ini diambil secara purposive sampling (sampel bertujuan), sehingga di dapatkan informan yang memenuhi kriteria dalam penelitian. Informan dalam penelitian ini berjumlah 5 orang responden tenaga kerja dan 3 orang responden dari manajemen sebagai triangulasi. Metode pengumpulan data 
dalam penelitian ini yaitu dengan tenaga kerja dibagian produksi, Kepala mengumpulkan data primer dan sekunder. tehnik tambang, Manajer produksi dan Ahli Pengumpulan data primer dilakukan K3.

dengan wawancara mendalam (indepth interview). Wawancara dilakukan dengan menggunakan pertanyaan terbuka yang dilakukan oleh peneliti sendiri tanpa bantuan dari orang lain, dimana jadwal wawancara sudah dibuat berdasarkan kesepakatan antara responden dan peneliti. Alat bantu yang digunakan peneliti pada saat melakukan wawancara berupa alat tulis, tape recorder untuk mencatat dan merekam informasi yang diperoleh, dan kamera. Data sekunder diperoleh melalui data - data dari perusahaan serta data awal hasil pengukuran iklim kerja.

Pengolahan dan analisis data pada penelitian ini menggunakan metode content analysis (analisis isi) yaitu pengumpulan data, reduksi data, verifikasi kemudian disajikan dalam bentuk deskriptif, kemudian dilakukan penarikan kesimpulan. Setelah itu dilakukan validitas yaitu derajat ketepatan antara data yang terdapat dilapangan tempat penelitian dan data yang dilaporkan oleh peneliti. Validitas pada penelitian ini dilakukan dengan triangulasi, yaitu teknik pemeriksaan data yang memanfaatkan sesuatu yang lain diluar data itu untuk keperluan pengecekkan atau sebagai pembanding terhadap data itu. Triangulasi sumber dilakukan dengan wawancara mendalam kepada 5 orang

HASIL PENELITIAN DAN

\section{PEMBAHASAN}

Karakteristik informan dalam penelitian ini, dimana informan utama dalam penelitian ini berjumlah 8 orang. 5 orang tenaga kerja di bagian produksi, dan 3 orang dari manajemen. Usia tenaga kerja yang khusus dibagian produksi antara 28 sampai 46 tahun dengan lama kerja antara 1 sampai 3 tahun dan tingkat pendidikan dari SMP sampai SLTA sederajat. Sedangkan 3 orang dari pihak manajemen, usianya antara 24 - 60 tahun dengan lama kerja antara 1 - 3 tahun dan tingkat pendidikan Diploma 3 - Strata1.

Informan dari manajemen bekerja non shift dengan jam kerja mulai jam 08.00 - 16.00. Informan dari tenaga kerja dibagian produksi menjalankan proses produksi dengan sistem kerja shift yang 
terbagi dalam 3 shift dengan lama kerja 8 jam. Shift pagi dari pukul $07.00-15.00$, shift sore dari pukul 15.00 - 23.00, dan shift malam dari pukul 23.00 - 07.00 . Pembagian shift kerja selama 1 minggu yaitu : 2 hari shift pagi, 2 hari shift sore, 2 hari shift malam dan 1 hari off.

\section{Heat Stress diarea Furnace}

Suhu di lingkungan kerja area furnace tergolong kategori panas, dengan temperatur di tempat produksi area furnace sebesar $34,9^{\circ} \mathrm{C}$ dan di area tapping $34,6^{\circ} \mathrm{C}$. Suhu ini melebihi nilai ambang batas yang diperkenankan menurut peraturan Menaker No.Per.13/Men/X/2011 dimana NAB iklim kerja bagi pekerja yang pengaturan waktu kerja setiap jam nya $0 \%-25 \%$ adalah sebesar $30,5^{\circ} \mathrm{C}$. Suhu panas ini dikarenakan dari aktifitas proses peleburan timah, dimana untuk mendapatkan timah yang cair ini : memerlukan suhu panas dengan titik lebur $1300^{\circ} \mathrm{C}$. Tenaga kerja yang bekerja dibagian produksi, tubuhnya akan mengeluarkan suhu panas karena proses metabolisme. Kontribusi kombinasi dari suhu panas tubuh dengan suhu panas dari iklim kerja ini disebut heat stress atau tekanan panas. Suhu panas ini akan menurunkan produktivitas yang akan membawa dampak negatif terhadap kesehatan dan keselamatan tenaga kerja.

Hasil wawancara kepada informan tenaga kerja, pada waktu melakukan aktivitas, mereka merasakan gejala-gejala seperti: panas, keringat berlebihan, badan lemas, mata berkunang-kunang, ada satu informan yang pernah merasakan pusing, mual dan pernah muntah, akibat dari panas tersebut. Seperti yang diungkapkan oleh informan dalam petikan wawancara berikut

“ Panas, pasti panas soalnya timahkan harus panas untuk lebur $1600^{\circ} \mathrm{C}$ an, kurang menyenangkanlah yang jelas panaslah, rasa ditubuh perubahan tubuh dadakan dari panas ke suhu biasa diluar tanur (furnace) atau dari suhu biasa ke panas, dari tanur ke luar tanur, badan e dak nyamen (badannya ngak nyaman), dak enak jadi dibadan, lemas, keringat becucuran... “(IU1)

Hal ini terjadi disebabkan karena adanya heat stress dilingkungan kerja, yaitu adanya suhu / iklim kerja yang panas dan berpadu padan dengan suhu panas yang dikeluarkan dari tubuh tenaga kerja sebagai akibat dari pelaksanaan kerja fisik yang berat.
Sebagai akibat masuknya energi panas ke lingkungan tempat kerja, maka dapat menimbulkan perubahan iklim di dalam lingkungan tempat kerja tersebut. Perubahan iklim/cuaca ini telah menyebabkan terjadinya tekanan panas (heat stress) yang akan diterima oleh 
tenaga kerja yang bekerja dilingkungan tempat kerja tersebut sebagai beban panas tambahan (disamping beban panas yang dihasilkan tubuh sebagai akibat pelaksanaan kerja), yang dapat mengakibatkan banyak pengaruh negatif kepada tenaga kerja baik yang berupa gangguan pekerjaan (pelaksanaan kerja) maupun gangguan kesehatan, yang berupa gangguan pekerjaan termasuk : kepala pusing, mata berkunang-kunang, perut mual, berkeringat, dan cepat lelah (Suma'mur, 1996)

Hasil wawancara mendalam kepada pihak manajemen bahwa manajemen menyadari adanya lingkungan kerja yang panas. Suhu di tempat kerja yang panas ini dikarenakan dari proses produksi yang mengharuskan adanya proses panas. Untuk peleburan suhu di dalam tanur $1300^{\circ} \mathrm{C}$ yang pada akhirnya dari proses peleburan ini akan mendapatkan hasil berupa timah cair. Oleh karena itu suhu yang panas ini tidak bisa dihindari oleh pekerja dibagian produksi.

Manusia merasa nyaman bekerja pada temperatur udara sekitar $20^{\circ} \mathrm{C}$ dan $27^{\circ} \mathrm{C}$ dan dalam situasi humiditas berkisar $35 \%$ sampai $60 \%$ (CCOHS, 2001). Kebanyakan orang tidak menyadari tentang kondisi suasana nyaman dalam ruangan. Hanya bila kondisi ini menyimpang dari batas kenyamanan, kita akan mengalami ketidaknyamanan. Rasa tak nyaman penting dalam biologis, karena menyebabkan orang mengalami langkah-langkah untuk mengembalikan keseimbangan suhu. Penyimpangan dari batas kenyamanan suhu menyebabkan perubahan secara fungsional yang meluas. Kelewat panas akan menyebabkan capek dan ngantuk yang mengurangi prestasi dan meningkatkan frekuensi kesalahan. Iklim kerja merupakan salah satu aspek yang cukup penting dalam suatu perusahaan. Iklim yang tidak tepat dapat menimbulkan gangguan kesehatan pada tenaga kerja, yang pada akhirnya akan menurunkan produktivitas.

Sistem kerja yang dilakukan oleh tenaga kerja pada saat melakukan aktivitas, tenaga kerja bekerja secara bergantian, hal ini bertujuan untuk mengurangi paparan panas. Pergantian ini merupakan inisiatif sendiri dari pekerja tidak ada standar dan aturan dari manajemen yang mengaturnya.

Pada kegiatan pengkajian resiko (risk assesment), hirarki pengendalian (hierarchy of control) merupakan salah satu hal yang sangat diperhatikan. Pemilihan hirarki pengendalian memberikan manfaat secara efektifitas dan efesiensi sehingga resiko menurun dan menjadi resiko yang bisa diterima (acceptable risk) bagi suatu organisasi. Dalam perusahaan ini, hirarki pengendalian yang dapat dilakukan adalah dengan cara administratif control ditujukan 
pengendalian dari sisi orang yang akan melakukan pekerjaan, dengan dikendalikan metode kerja diharapkan orang akan mematuhi, memiliki kemampuan dan keahlian cukup untuk menyelesaikan pekerjaan secara aman. Jenis pengendalian yang dapat dilakukan diperusahaan ini adalah bagian manajemen membuat, mengatur dan mengawasi dengan teratur pergantian kerja setiap tenaga kerja dengan cara minimalisir waktu paparan terhadap panas yang berguna untuk mengurangi interaksi paparan panas dengan tenaga kerja.

Lingkungan kerja yang panas akan menurunkan produktivitas kerja, juga akan membawa dampak negatif terhadap kesehatan dan keselamatan kerja, hal ini bila tidak dilakukan upaya pengendalian akan menimbulkan gangguan terhadap suasana kerja dan berpengaruh terhadap keselamatan dan kesehatan tenaga kerja.

Pengendalian suhu panas yang dilakukan oleh tenaga kerja berdasarkan hasil wawancara mendalam kepada informan adalah tenaga kerja mencari tempat yang dingin atau mencari angin segar disekitar tempat kerja setelah melakukan aktivitas yang berhubungan dengan panas, seperti memasukkan material ke dalam tanur/furnace, melakukan rubbling, dan melakukan tapping. Upaya lain yang dilakukan 3 dari 5 informan tenaga kerja adalah dengan membuka baju setelah melakukan aktivitas yang terpapar suhu panas, dalam hal ini dimaksudkan untuk penguapan karena berkeringat banyak.

Tekanan panas juga berpengaruh kepada tingkah laku tenaga kerja, tingkah laku yang umumnya dihubungkan dengan tekanan panas adalah upaya untuk mengurangi pemajanan, seperti membuka baju yang dimaksudkan untuk meningkatkan penguapan dari tubuh, melambatkan gerakan saat bekerja atau istirahat sebentar untuk menurunkan kecepatan metabolisme (Moeljosoedarmo, 2008).

\section{Pengendalian Heat Stress dengan Cara Training}

Metode pengendalian heat stress salah satunya dengan cara training yaitu berupa pendidikan atau pelatihan mengendalikan tekanan panas dan resiko panas dilingkungan kerja yang beriklim panas.

Hasil penelitian, pelaksanaan pengendalian heat stress pada tenaga kerja dengan cara training (pendidikan/latihan) diperusahaan yang sudah dijalankan berupa safety induksi untuk tenaga kerja baru. Untuk tenaga kerja lama, ada yang pernah mengikuti training tentang penanggulangan kebakaran yang diberikan oleh dinas pemadam kebakaran dan pelatihan tentang P3K yang disampaikan oleh dokter 
puskesmas serta penyuluhan tentang K3 kondisi fisik tenaga kerja (moeljosoedarmo, umum yang disampaikan oleh ahli K3. 2008).

Namun pelatihan ini belum rutin

Terkait pelatihan berdasarkan hasil dilaksanakan, selama perusahaan berdiri, penelitian, informan baik tenaga kerja baru pelatihan itu saja yang diadakan dan maupun ahli K3 nya menginginkan adanya untuk pelatihan khusus pengendalian heat pelatihan-pelatihan untuk keselamatan dan stress bagi tenaga kerja yang bekerja dilingkungan kerja panas belum pernah dilaksanakan.

Training (pendidikan/latihan) adalah pendidikan atau latihan bagi calon tenaga kerja sebelum ditempat kan (preplacement) dan setelah ditempatkan yang dilaksanakan secara berkala (periodik). Pendidikan seperti ini dilaksanakan baik untuk para calon tenaga kerja yang akan bekerja dilingkungan tempat kerja panas atau para tenaga kerja yang bekerja dilingkungan kerja panas maupun untuk supervisornya. Informasi yang menguntungkan yang dapat diperoleh dari pendidikan ini adalah cara-cara mengendalikan tekanan panas dan caracara untuk mengendalikan resiko yang berhubungan dengan panas.

Pendidikan sebelum penempatan dapat digabung dengan pendidikan (latihan kerja) yang lain termasuk keselamatan kerja dan latihan ketrampilan yang lain. Suatu bahan pelengkap latihan kepada peserta sebelum penempatan adalah pemberian nasehat oleh pegawai kesehatan tentang hal - hal yang berhubungan dengan kesehatan kerja, menambah wawasan dan tehnik kerja terbaru, menghindari terjadinya bahaya, memperkecil terjadinya kecelakaan serta antisipasi untuk penanganan kondisi dilapangan khususnya tempat kerja yang berhubungan dengan suhu kerja yang panas.

Menurut Noe, et all mengemukakan pelatihan merupakan suatu usaha yang terencana untuk menfasilitasi pembelajaran tentang pekerjaan yang berkaitan dengan pengetahuan, keahlian dan perilaku oleh para pekerja. Menurut Gomes pelatihan adalah setiap usaha untuk memperbaiki performansi pekerja pada suatu pekerjaan tertentu yang sedang menjadi tanggung jawabnya, atau satu pekerjaan yang ada kaitannya dengan pekerjaannya. Untuk mengembangkan kompetensi, SDM yang bermutu harus selalu berusaha mengikuti perkembangan ilmu pengetahuan dan teknologi serta pelatihan - pelatihan yang mendukung. Tenaga pelaksana dianalisis berdasarkan kuantitas dan kualitas dengan latar belakang pendidikan, lama kerja, dan pelatihan yang pernah diikuti. Tenaga adalah orang yang bertanggung jawab mengerjakan sesuatu dan mengkoordinir 
program diwilayah kerjanya (Pranoto, Said, 2008)

\section{Pengendalian heat stress dengan penggantian cairan}

Berdasarkan hasil penelitian dan observasi dilapangan, bahwa upaya pengendalian dengan penggantian cairan yang dilaksanakan dilingkungan perusahaan dengan selalu menyediakan air minum untuk tenaga kerja dan disediakan dilingkungan tempat kerja.

Air minum harus disediakan bagi tenaga kerja yang bekerja dilingkungan kerja panas, dengan cara seperti itu mereka di dorong untuk minum dalam jumlah sedikit-sedikit tapi sering dilakukan, misalnya 1 gelas $(200 \mathrm{cc}$ ) setiap $20-30$ menit (moeljosoedarmo,2008). Sebagai pengganti cairan yang hilang kebutuhan air dan garam perlu mendapat perhatian. Dalam lingkungan kerja yang panas dengan jenis pekerjaan berat diperlukan sekurangkurangnya 2,8 liter air minum bagi seorang tenaga kerja (suma'mur, 1981).

Air minum merupakan unsur pendingin tubuh yang penting dalam lingkungan panas terutama bagi tenaga kerja yang terpapar oleh panas yang tinggi sehingga banyak mengeluarkan keringat (suma'mur, 2003)

Hasil wawancara mendalam kepada informan bahwa, kebiasaan yang dilakukan oleh tenaga kerja adalah minum pada saat haus saja dan biasanya setelah melakukan aktivitas yang terpapar dengan suhu panas seperti memasukkan material ke dalam anur, melakukan rubbling dan tapping. 1 dari 5 informan mengungkapkan bahwa setelah melakukan aktivitas, minum bisa mencapai 5 gelas $(1000 \mathrm{cc})$. Konsumsi cairan tenaga kerja rerata selama 8 jam kerja adalah $1600-2200 \mathrm{cc}$.

Kehilangan air yang banyak dari tubuh dalam bentuk keringat adalah untuk tujuan pendinginan dengan penguapan. Kehilangan dapat mencapai 6 liter air dalam 1 hari. Air yang hilang ini harus diganti dengan minum air dingin atau minuman yang berasa seperti es teh encer, atau dengan rasa jeruk atau cairan minuman yang dijual (minuman yang mengandung elektrolit). Air minum harus disediakan bagi tenaga kerja yang bekerja dilingkungan panas, dengan cara seperti itu mereka di dorong untuk minum dalam jumlah sedikit-sedikit tapi sering dilakukan (moeljosoedarmo, 2008).

Dari hasil penelitian semua informan mengungkapkan, untuk instruksi/cara atau anjuran untuk pola minum di lingkungan kerja yang panas, tidak ada petunjuk atau anjuran minum untuk tenaga kerja, inisiatif dari tenaga kerja tersebut kalau haus mereka minum sendiri.

Menurut Siswanto, kebiasaan minum hanya ketika haus kurang baik 
karena respon haus seseorang lebih lambat daripada defisit cairan. Bagi tenaga yang bekerja pada lingkungan panas sebaiknya minum sesering mungkin tanpa menunggu haus, dianjurkan minum 200 - 300cc setiap 30 menit sekali agar cairan tubuh selalu dalam keadaan seimbang (siswanto,1991). Air minum sebaiknya diberikan dalam jumlah kecil tapi frekuensinya lebih sering, dengan interval 20 - 30 menit dengan suhu optimum air adalah $10^{\circ} \mathrm{C}-21^{\circ} \mathrm{C}$ (almatsier,2003)

NIOSH menyarankan agar tenaga kerja minum sebanyak 150 - 200cc setiap 15 - 20 menit. Air minum sebaiknya disimpan ditempat dingin dan ditempatkan dekat dengan tempat kerja sehingga tenaga kerja dapat mengambil tanpa meninggalkan lingkungan kerja. tenaga kerja yang hanya minum bila merasa haus saja tidak akan memberikan hasil yang memuaskan (moeljosoedarmo, 2008).

Hasil penelitian dari Triyanti pada pekerja binatu dan dapur hotel $\mathrm{X}$ bahwa sebanyak $29,3 \%$ pekerja mengalami kristalisasi urin dengan jenis kalsium oksalat, asam urat dan amorf phospat, secara statistik terdapat hubungan yang signifikan antara variabel kebiasaan minum dengan terjadinya kristalisasi urin (Triyanti, 2008).

Hasil penelitian dari Suwondo, dkk dengan metode quasi eksperimen yaitu pada pola 1 pekerja minum seperti biasa tidak dilakukan intervensi apapun oleh peneliti, pada pola 2 pekerja diberikan air minum $250 \mathrm{ml}$ perjam sesuai dengan perkiraan kebutuhan air pada lingkungan kerja panas dan didapatkan hasil bahwa konsumsi air minum pola 2 memberikan kontribusi yang positif terhadap tekanan darah pekerja sehingga dapat memperbaiki penurunan tekanan darah pekerja akibat bekerja dilingkungan kerja yang panas (suwondo,lestantyo, 2008)

Bagi tenaga kerja yang belum beraklimatisasi sebaiknya air minum mengandung garam dengan kadar 0,2\%, sedang bagi tenaga kerja yang sudah beraklimatisasi kadar garam dalam air minum sebesar 0,1\%. Menurut Ramsey pemberian tablet garam dapur tidak dianjurkan, sebaiknya garam ditambahkan pada makanan saja, karena pemberian garam melalui air minum ternyata menyebabkan beberapa orang merasa mual, sehingga akibatnya para tenaga kerja akan mengurangi minum (moeljosoedarmo, 2008)

Penyediaan air minum adalah salah satu bentuk sarana prasarana yang disediakan oleh perusahaan untuk kebutuhan tenaga kerja apalagi pekerja yang bekerja dilingkungan kerja yang panas, hasil observasi dan wawancara mendalam yang peneliti lakukan, perusahaan menyediakan air minum dan 
selalu ada stok nya. Hal ini adalah salah satu usaha yang dilakukan perusahaan untuk upaya pengendalian panas dengan penggantian cairan untuk tenaga kerja, hanya saja cara/ instruksi atau anjuran pola minum yang sebaiknya untuk tenaga kerja yang belum ada. Untuk itu pihak manajemen sangat mengharapkan adanya masukkan dari peneliti untuk anjuran atau cara sebaiknya untuk penggantian cairan.

\section{Pengendalian Heat Stress dengan Cara}

\section{Aklimatisasi}

Berdasarkan hasil penelitian dengan wawancara mendalam terhadap semua informan, aklimatisasi atau penyesuaian tubuh terhadap tenaga kerja belum dilaksanakan. Untuk Aklimatisasi atau penyesuaian tubuh tenaga kerja sebaiknya dilakukan secara bertahap. Hasil wawancara kepada informan dari tenaga kerja dan dari manajemen bahwa tenaga kerja yang baru biasanya diberi pengarahan terlebih dahulu, melalui pengenalan (safety induksi) tentang tempat kerja, resiko dan bahaya dilingkungan kerja serta sosialisasi tempat kerja, setelah itu tenaga kerja baru, langsung ikut membantu pekerjaan yang ringan - ringan terlebih dahulu seperti memasukkan material ke dalam tanur dengan cara menyekop yang dipandu oleh kepala regu atau tenaga kerja yang lama. Tenaga kerja yang baru setelah mendapatkan pengarahan langsung bekerja sesuai jam kerja yaitu 8 jam kerja.

Menurut J. Ramsey lama adaptasi dapat dicapai dalam 5-7 hari, aklimatisasi menjadi maksimal setelah 12-14 hari. Bagi tenaga kerja baru, maka proses aklimatisasi sebaiknya dilangsungkan secara bertahap sebagai berikut: Pada hari pertama selama 2 jam, disini proses aklimatisasi baru 20\%, dan proses ini ditingkatkan pada hari-hari kerja berikutnya. Pada hari kedua tenaga kerja bekerja dilingkungan tempat kerja yang panas selama 4 jam, (aklimatisasi dinaikkan dari $20 \%$ menjadi $40 \%$ ). Sedangkan pada hari ketiga tenaga kerja bekerja selama 6 jam (aklimatisasi mencapai 60\%). Demikian seterusnya, sehingga akhirnya pada hari ke lima, aklimatisasi telah mencapai $100 \%$ (tenaga kerja bekerja dilingkungan tempat kerja panas selama 8 jam atau selama 1 shift kerja) (moeljosoedarmo, 2008).

Setiap calon tenaga kerja yang akan bekerja dilingkungan tempat kerja panas harus melakukan penyesuaian fisiologis terhadap pajanan panas secara bertahap. Orang Indonesia pada umumnya beraklimatisasi iklim tropis yang suhunya sekitar $28-32^{\circ} \mathrm{C}$ dengan kelembaban sekitar $85-95 \%$ bahkan mungkin lebih. Aklimatisasi terhadap suatu iklim (cuaca) berarti penyesuaian yang terjadi pada seseorang terhadap suatu iklim (cuaca) 
tertentu sehingga menjadi terbiasa terhadap iklim (cuaca) tersebut, dan kondisi fisik, faal dan psikis tidak mengalami efek buruk dari iklim (cuaca) dimaksud. Aklimatisasi merupakan suatu proses yang pada akhirnya tercapai kesesuaian antara faktor manusia dan faktor iklim (cuaca). Proses penyesuaian terutama penting saat awal proses aklimatisasi, yang memerlukan perhatian khusus adalah minggu - minggu pertama seseorang berada ditempat dengan iklim (cuaca) baru (suma'mur, 2009)

Berdasarkan hasil wawancara mendalam kepada informan bahwa, pernah ada tenaga kerja yang baru masuk mengundurkan diri tidak masuk lagi karena tidak tahan panas dari api peleburan. Tenaga kerja yang tidak beraklimatisasi, namun langsung bekerja di lingkungan tempat kerja panas akan mengalami tandatanda stress, seperti rasa tidak nyaman, dan lebih lanjut timbul peningkatan denyut nadi (denyut jantung), suhu inti tubuh meningkat dan timbul keluhan-keluhan sakit kepala, pusing, atau perut mual. Jadi dengan pemaparan berulang akan timbul faktorfaktor yang lebih menguntungkan yaitu terjadinya aklimatisasi.

Pekerjaan dan tempat kerja pada umumnya beriklim kerja panas yang biasanya tekanan panasnya melebihi keadaan sehari - hari kehidupan pada umumnya. Pekerja baru yang mulai bekerja pada lingkungan kerja dengan tekanan panas demikian akan mengalami proses aklimatisasi terhadap intensitas paparan panas yang sebelumnya tidak pernah mengalaminya. Untuk melindungi tenaga kerja baru demikian, perlu diatur agar pekerjaan khususnya pada waktu minggu minggu pertama pekerjaan dilakukan secara bertahap baik mengenai lama maupun beban kerjanya. Suhu tinggi dapat mengakibatkan heat exhaustion. biasanya terjadi oleh karena lingkungan yang sangat panas, terutama bagi yang belum beraklimatisasi terhadap iklim (cuaca) panas. Penderita sangat banyak berkeringat, sedangkan temperatur badan normal atau sub normal. Tekanan darah menurun dan nadi lebih cepat, badan lemah dan bisa sampai pingsan (suma'mur, 2009)

Sebagai upaya preventif terhadap penyakit atau gangguan kesehatan akibat lingkungan kerja bersuhu tinggi, yang paling penting adalah aklimatisasi pekerja kepada lingkungan.

\section{SIMPULAN}

Pengendalian heat stress pada tenaga kerja sangat penting untuk dilaksanakan, apabila tidak dilaksanakan maka akan berdampak pada kesehatan dan keselamatan pada tenaga kerja. Pengendalian dengan mengadakan training (pendidikan/latihan) tentang mengendalikan tekanan panas dan resiko panas 
dilingkungan kerja yang beriklim panas belum dilaksanakan secara rutin

Terkait pelatihan, tenaga kerja maupun ahli K3 nya menginginkan adanya pelatihan pelatihan untuk keselamatan dan kesehatan kerja, menambah wawasan dan tehnik kerja terbaru, menghindari terjadinya bahaya, memperkecil terjadinya kecelakaan serta antisipasi untuk penanganan kondisi dilapangan khususnya tempat kerja yang berhubungan dengan suhu kerja yang panas. Pengendalian dengan penggantian cairan, sudah dijalankan oleh perusahaan dengan selalu menyediakan air minum dilingkungan tempat kerja, hanya saja instruksi/ anjuran atau pola untuk minum (penggantian cairan) belum ada. Pengendalian dengan aklimatisasi (penyesuaian suhu tubuh bagi pekerja baru) belum dilaksanakan, pekerja baru langsung ikut bekerja dan sesuai dengan jam kerjanya.

\section{KEPUSTAKAAN}

Almatsier.S. Prinsip dasar ilmu gizi. Jakarta: PT. Gramedia Pustaka Utama, 2003

American Conference Of Govermental Industrial Hygienists (ACGIH). Heat Stress and Strain; 2001.

Canadian Centre For Occupational Health (CCOHS). Hot Environments Health Effects, Ontario and safety; 2001.

Cut Zumali. Pengertian pelatihan dalam manajemen sumberdaya manusia. http://id.wikipedia.org/wiki/pelatihan. di download 30 Juni 2013

Lapau.B. Metode Penelitian Kesehatan: Metode Ilmiah Penulisan Skripsi, Tesis, dan Disertasi. Jakarta: Yayasan Pustaka Obor Indonesia; 2012.

Moeljosoedarmo.S. Higiene Industri. Jakarta: Fakultas Kedokteran Universitas Indonesia; 2008.

Pranoto H. sB, Said Al. Minaut. metode efektif pemecahan masalah dan pengambilan keputusan. Jakarta: Penerbit PPM; 2008.

Peraturan Menteri Tenaga Kerja dan Transmigrasi Tentang Nilai Ambang Batas Faktor Fisika dan Faktor Kimia di Tempat Kerja;2011

Siswanto.A. Tekanan panas. Balai Hiperkes dan keselamatan kerja ; Surabaya, 1991

Suma'mur.PK. Keselamatan kerja dan pencegahan kecelakaan. Jakarta: CV.Haji Masagung, 1981

Suma'mur. Higiene Perusahaan dan Kesehatan Kerja. Jakarta: PT. Toko Gunung Agung; 1996.

Suma'mur. PK. Keikutsertaan Masyarakat Dalam Mengkomunikasikan, Sosialisasi dan Motivasi Pelaksanaan Keselamatan dan Kesehatan Kerja. Yogyakarta: Bigraff Publishing, 2003

Suma'mur. Higiene Perusahaan dan Kesehatan Kerja (Hiperkes). Jakarta: CV. Sagung Seto; 2009.

Sugiyono. Memahami penelitian kualitatif. Bandung: CV.Alfabeta, 2013

Suwondo.A, Lestantyo.D, Yulisnawati. Perbedaan tekanan darah pada pekerja yang terpapar panas di industri sale pisang suka senang kabupaten ciamis. Jurnal promosi kesehatan Indonesia Vol.3/No.1/ Januari 2008

Triyanti.F. Hubungan Faktor - Faktor Heat Stress dengan Terjadinya Kristalisasi Urin Pada Pekerja Binatu dan Dapur Hotel X Medan. Medan: USU; 2008. 